\title{
Colloidal synthesis of NaYF4 nano- and microparticles by sacrificial template method
}

\section{Leonardo J. da Cruz*, Gabriela Guida, Paulo C. de Sousa Filho}

\begin{abstract}
Lanthanide-doped sodium yttrium tetrafluoride nanoparticles show intense upconversion emissions which raise great attention in a variety of luminescence applications. This host lattice shows specially attractive properties in its hexagonal phase, which normally requires high temperature reactions and complex procedures to be synthesized. In this work, we synthesized nano- and micro-sized NaYF4 particles with controllable cubic or hexagonal structure via sacrificial colloidal template method under mild conditions of $50^{\circ} \mathrm{C} / 1$ atm in a $3 \mathrm{~h}$-long reaction.
\end{abstract}

\section{Key words:}

Upconversion luminescence, sacrificial template, NaYF4

\section{Introduction}

Lanthanide-doped upconversion nanoparticles (UCNPs) have attracted great attention due to its chemical and optical properties, such as non-autofluorescence, long-lived luminescence, narrow emission lines, high photo-bleaching thresholds and low toxicity [1]. NaYF 4 crystals can occur as both cubic $(\alpha)$ and hexagonal $(\beta)$ solids displaying distinct behavior concerning upconversion luminescence efficiency [2]. Besides its enhanced UC luminescence, the $\beta-\mathrm{NaYF}_{4}$ is more thermodynamically stable than the $\alpha$-phase. This way, the $\alpha$-to- $\beta$ phase transition normally requires highly energetic conditions of temperature/pressure for precipitation procedures, usually assisted by surface ligands and stabilizers [3]. The chemical conversion reactions of nanoparticles, in which sacrificial templates change to another composition usually accompany morphological changes such as cavity formation. This is common in reactions involving diffusion pairs, which can form pores and voids in the solid depending on the diffusibility difference. This cavity formation phenomenon is called Kirkendall effect, that has great potential in biological application such as drug delivery, imaging and biosensing [4]. Hence, here we applied a sacrificial template method for the structure control of $\mathrm{NaYF}_{4}$ nanoparticles in mild conditions.

\section{Results and Discussion}

Rare earth (RE) hydroxycarbonates $\left(\mathrm{Y}_{0.95}, \mathrm{Eu}_{0.05}\right) \mathrm{CO}_{3} \mathrm{OH}$ prepared from $\mathrm{RE}\left(\mathrm{NO}_{3}\right)_{3}$ by an urea-based precipitation process were used as template for the synthesis of $\mathrm{NaYF}_{4}$. The formation of $\mathrm{NaYF}_{4}$ initially occurs on the surface of $\left(\mathrm{Y}_{0.95}, \mathrm{Eu}_{0.05}\right) \mathrm{CO}_{3} \mathrm{OH}$ particles via the Kirkendall effect, where hydroxycarbonate particles act as a morphology template reacting with fluoride ions from $\mathrm{NaBF}_{4}$ precursors. Adjusting the solvent composition (water/ethylene glycol) enabled the control of the dominant crystalline phase, which was achieved in very mild conditions $\left(50^{\circ} \mathrm{C}, 1 \mathrm{~atm}\right)$. We were able to synthesize $\beta-\mathrm{NaYF}_{4}$ nanoparticles from a $\left(\mathrm{Y}_{0.95}, \mathrm{Eu}_{0.05}\right) \mathrm{CO}_{3} \mathrm{OH}$ template with resemblance in size as shown by the Dynamic Light Scattering (DLS) results in Figure 1-A comparing the precursor and product particles. Figure 1-B shows the X-Ray Diffraction (XRD) diffractogram of Product 1. The diffraction peaks of Product 1 match he $\beta-\mathrm{NaYF}_{4}$ reference indexed as JCPDS\#160334.

Figure 2-A shows the DLS analysis comparing Product 2 and another $\left(\mathrm{Y}_{0.95}, \mathrm{Eu}_{0.05}\right) \mathrm{CO}_{3} \mathrm{OH}$ precursor particles size. Again, we could see the size similarity to its template in $\alpha$ -
$\mathrm{NaYF}_{4}$ as well. The XRD diffractogram in Figure 2 confirms the formation of the cubic phase $\mathrm{NaYF}_{4}$, where its peaks match the reference JCPDS\#77-2042.
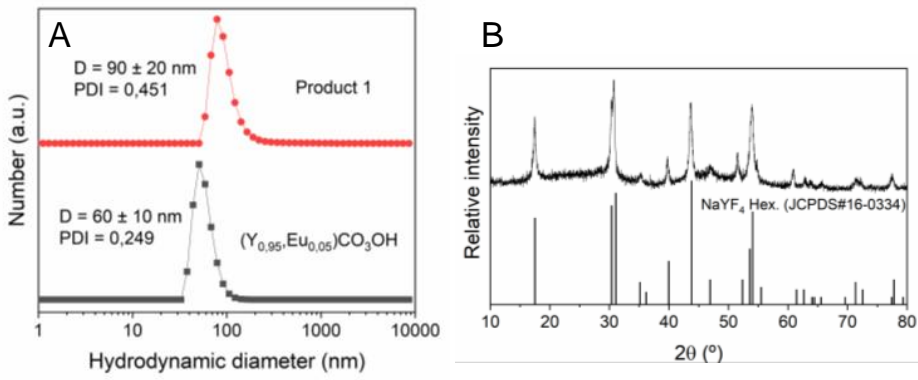

Figure 1. (A) DLS analysis of $\left(\mathrm{Y}_{0.95}, \mathrm{Eu}_{0.05}\right) \mathrm{CO}_{3} \mathrm{OH}$ precursor and Product 1. (B) XRD diffractogram of Product 1 with matching peaks to $\beta-\mathrm{NaYF}_{4}$ reference.
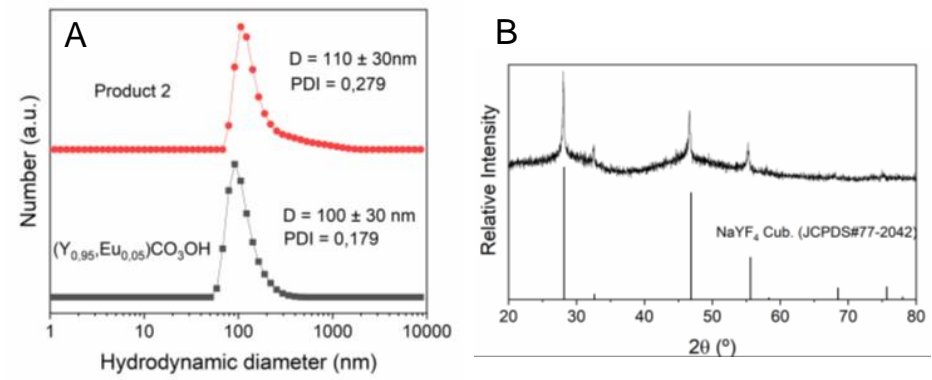

Figure 2. (A) DLS analysis of $\left(\mathrm{Y}_{0.95}, \mathrm{Eu}_{0.05}\right) \mathrm{CO}_{3} \mathrm{OH}$ precursor and Product 2. (B) XRD diffractogram of Product 2 with matching peaks to $\alpha-\mathrm{NaYF}_{4}$ reference.

\section{Conclusions}

The results obtained herein show the possibility to obtain $\alpha$ - and $\beta-\mathrm{NaYF}_{4}$ nanoparticles via sacrificial template method that has a great control over particles size and structure. To validate morphology and structure control, further electron microscopy analyses will be conducted along with evaluation of luminescent properties.

\section{Acknowledgement}

The authors thank the financial support from $\mathrm{CNPq}$, CAPES, FAEPEX and FAPESP.

[1] Ye, S. et al.; Mater. Res. Bull. 2018, 103, 279.

[2] Duan, C. et al.; J. Mater. Chem. B, 2018, 6, 192.

[3] Lv, R. et al.; Inorg. Chem. 2014, 53, 998.

[4] Anderson, B. D. et al.; Nanoscale, 2014, 6, 12195 - 13256 